\title{
Analisa Momen Tensor dan Mekanisme Pusat Gempa Bumi Wilayah Maluku Utara Sepanjang Tahun 2016 dengan Magnitude $\geq 5$ SR Memanfaatkan Program ISOLA-GUI
}

\author{
Hardiansyah Pratama dan Bagus Jaya Santosa \\ Departemen Fisika, Fakultas Ilmu Alam, Institut Teknologi Sepuluh Nopember (ITS) \\ e-mail:bjs@physics.its.ac.id
}

\begin{abstract}
Abstrak - Penelitian dengan fokus analisa momen tensor dan pola bidang patahan dilakukan pada gempa bumi Wilayah Maluku Utara pada tahun 2016 magnitude $\geq$ 5S R dengan memanfaatkan program IS OLA-GUI. Penelitian dilakukan dengan tujuan untuk menentukan nilai momen tensor gempa bumi tektonik dan bentuk pola bidang patahan pada Wilayah Maluku Utara dengan program ISOLA-GUI. Prinsip program ini mengolah tiga komponen gelombang seismik yang terekam dalam seismogram. Data berupa gelombang diolah sesuai masing-masing event gempa yang terjadi dan digunakan perhitungan fungsi Green serta inversi. Pada tahap inversi digunakan 4 filter f1, f2, f3, f4 yang diisi sesuai event. Plotting untuk hasil dilakukan setelah tahap inversi dan didapatkan nilai variance reduction $0.87,0.99,0.53$, 0.82, 0.92, dan 0.62. Plot selanjutnya berupa nilai momen tensor beserta pola bidang patahan yang disimbolkan dengan beachball. Pengolahan tersebut dilakukan pada seluruh event gempa.
\end{abstract}

Kata Kunci-ISOLA-GUI, Fungsi Green, Inversi, Plotting, Beachball, Variance Reduction.

\section{PENDAHULUAN}

$\mathrm{I}$ NDONESIA merupakan salah satu negara di Asia Tenggara yang terletak diantara 6 derajat LU - 11 derajat LS dan diantara 95 derajat BT - 141 derajat BT. Kondisi wilayah Indonesia yang terletak dalam lingkupan Ring of Fire dan tepat berada pada lempeng Pasifik, Indo-Australia dan Eurasia sangat berpengaruh dalam tingkat kebencanaan. Akibatnya banyak sekali event gempa bumi bahkan tsunami yang terjadi. Gempa bumi yang terjadi meliputi gempa tektonik maupun vulkanik. Pada penelitian ini, pengamatan dipusatkan pada gempa bumi tektonik. Gempa bumi tektonik sendiri adalah gempa yang disebabkan adanya pergeseran-pergeseran di dalam bumi secara tiba-tiba. Peristiwa gempa bumi tektonik sangat erat hubungannya dengan teori tektonik lempeng mengenai pembentukan pegunungan yang biasanya diikuti dengan pembentukan sesar-sesar baru. Jikalau tegangan-tegangan mengakibatkan sesar-sesar lama yang sudah tidak aktif, aktif kembali dengan melakukan pergerakan yang cukup besar maka dapat menyebabkan terjadi gempa bumi tektonik [1].

Wilayah Maluku Utara merupakan salah satu daerah di Indonesia dengan tingkat aktifitas seismik yang besar. Hal tersebut dikarenakan Keadaan tektonik Maluku Utara merupakan daerah tektonik yang kompleks, dibangun oleh interaksi antara lempeng Filipina di utara, lempeng Pasifik di timur, lempeng Eurasia dibarat, dan lempeng Indo-Australia di

\section{Schematic diagram of a focal mechanism}

A

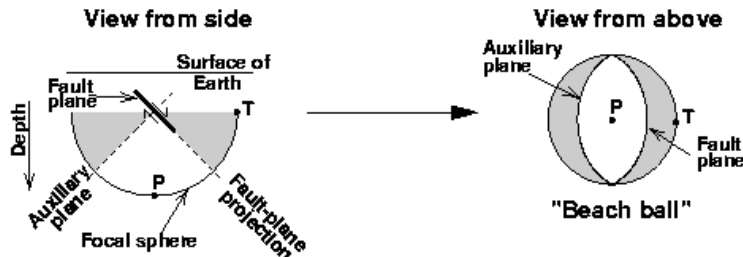

B
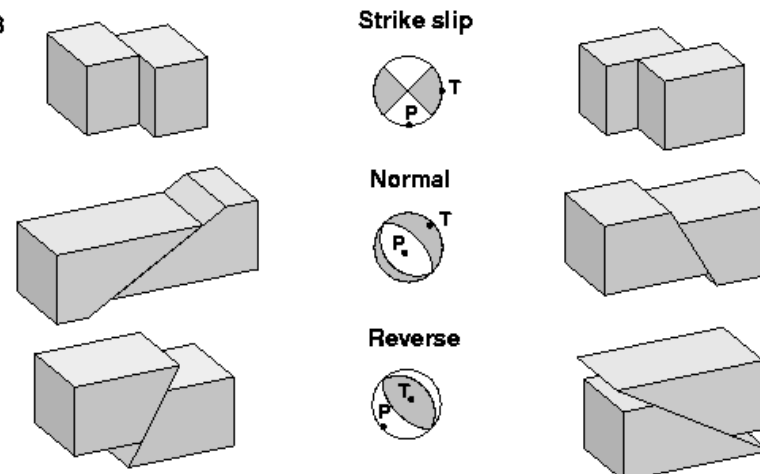

Normal
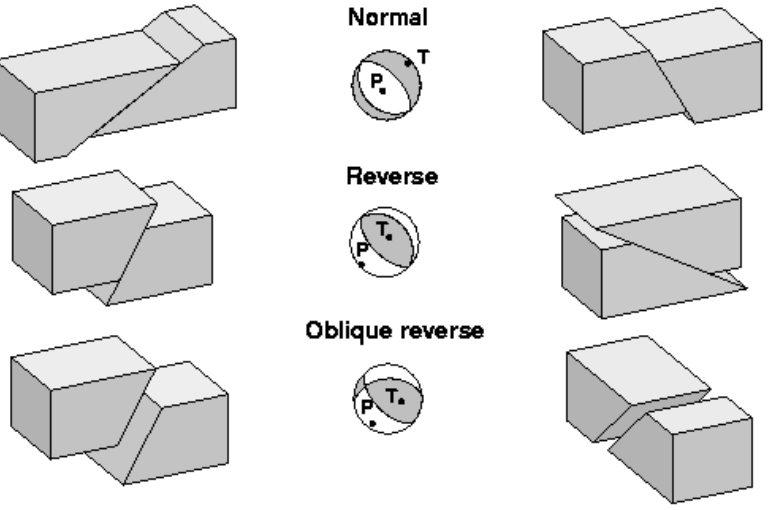

USGS, 1996

Gambar 1. Skema diagram dari mekanisme fokus gempa. (A) Pola beachball terhadap proyeksi bidang sesar dilihat dari samping. (B) Pola beachball dilihat dari atas. (USGS).

selatan. Batas selatannya merupakan sistem patahan Sorong dari Papua ke Sulawesi yang panjangnya sekitar 800 km kearah Sulawesi dan 1500 km sepanjang tepiutara Papua kearah Papua Nugini. sebelah barat dibatasi oleh Laut Maluku dan di timur laut dibatasi oleh ujung selatan Palung Filipina serta timur berbatasan dengan perluasan ke utara Patahan Sorong. Keadaan tektonik yang demikianlah yang membuat Wilayah Maluku Utara sering dilanda gempa bumi [2].

Gempa bumi terjadi akibat adanya gerakan suatu sesar dengan karakter gerak tertentu [3]. Karakteristik pergerakan sesar dibagi menjadi dua, sesarmendatar (strike slip fault) dan sesartidak mendatar (dip slip). 
(a)

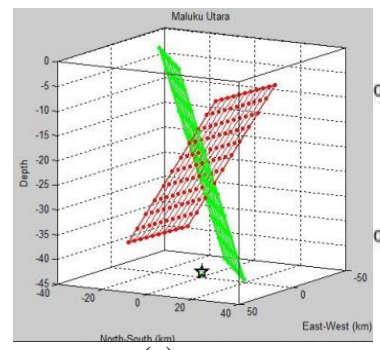

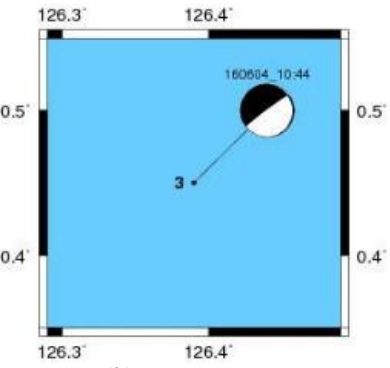

(b)
Gambar 2. (a) Orientasi bidang patahan. (b) Beachball sebagai representasi pola bidang sesar pada event 04/06/2016 dengan origin time 10:44:13 WIB.

Tabel 1.

Data event yang terjadi di Maluku Utara

\begin{tabular}{ccccccc}
\hline \hline No & Tanggal & Jam & Latt & Long & Mag & Depth \\
\hline 1 & $2016-10-27$ & $08: 17: 51$ & 1.42 & 125.76 & 5.7 & 82 \\
2 & $2016-10-09$ & $14: 46: 27$ & 1.78 & 127.49 & 5.7 & 137 \\
3 & $2016-06-19$ & $05: 00: 15$ & 1.02 & 126.21 & 5.1 & 61 \\
4 & $2016-06-07$ & $19: 15: 17$ & 1.36 & 126.34 & 6.3 & 47 \\
5 & $2016-06-04$ & $10: 44: 13$ & 0.45 & 126.39 & 5.4 & 44 \\
6 & $2016-03-29$ & $09: 18: 13$ & 2.42 & 126.16 & 5.3 & 78 \\
\hline \hline
\end{tabular}

Tabel 2.

Model Bumi Haslinger-Santosa(H-S)

\begin{tabular}{ccccccc}
\hline \hline No & $\begin{array}{c}\mathrm{V}_{\mathrm{p}} \\
(\mathrm{km} / \mathrm{s})\end{array}$ & $\begin{array}{c}\text { Kedalaman } \\
(\mathrm{km})\end{array}$ & $\begin{array}{c}\mathrm{V}_{\mathrm{s}} \\
(\mathrm{km} / \mathrm{s})\end{array}$ & $\begin{array}{c}\text { Massa } \\
\text { Jenis }\end{array}$ & $\mathrm{Q}_{\mathrm{p}}$ & $\mathrm{Q}_{\mathrm{s}}$ \\
\hline 1 & 2.31 & 0.0 & 1.300 & 2.500 & 300 & 150 \\
2 & 4.27 & 1.0 & 2.400 & 2.900 & 300 & 150 \\
3 & 5.52 & 2.0 & 3.100 & 3.000 & 300 & 150 \\
4 & 6.23 & 5.0 & 3.500 & 3.300 & 300 & 150 \\
5 & 6.41 & 16.0 & 3.600 & 3.400 & 300 & 150 \\
6 & 6.70 & 33.0 & 4.700 & 3.400 & 300 & 150 \\
7 & 8.00 & 40.0 & 4.760 & 3.500 & 1000 & 500 \\
\hline \hline
\end{tabular}

Sesar mendatar merupakan sesar dengan arah gerak blok sesar yang horizontal. Sesar mendatar dibagi menjadi dua, Right Lateral yang bergerak mendatar searah jarum jam dan Left Lateral dengan arah gerak mendatar berlawanan arah jarum jam (Gambar 1). Sesar tidak mendatar merupakan sesar dengan arah gerak blok secara vertikal atau miring. Macammacam jenis sesartidak mendatar yaitu Normal Fault atau sesar turun, Reverse Fault atau sesar naik, dan Oblique Fault adalah sesaryang mempunyai gerak secara diagonal karena gabungan dari sesar horizontal dan vertikal [4].

Model gerak ses ar dan karakter sesar penyebab gempa bumi dapat diketahui berdasarkan momen tensor gempa bumi. Momen tensorini digunakan untuk menggambarkan arah gaya penyebab gempa bumi. Konsep momen tens or dapat memberi deskripsi yang lengkap tentang gaya dari sumber titik seismik. Berdasarkan hal tersebut, studi ini dilakukan untukmenganalis a momen tensor gempa bumi dan pola bidang patahan Wilayah Maluku Utara dengan menggunakan program ISOLA-GUI [5].

\section{METODE PENELITIAN}

\section{A. Pengambilan Data}

Data yang akan diolah terlebih dahulu diunduh pada sumber webdc.eu. Data yang diunduh berupa event gempa bumi dan

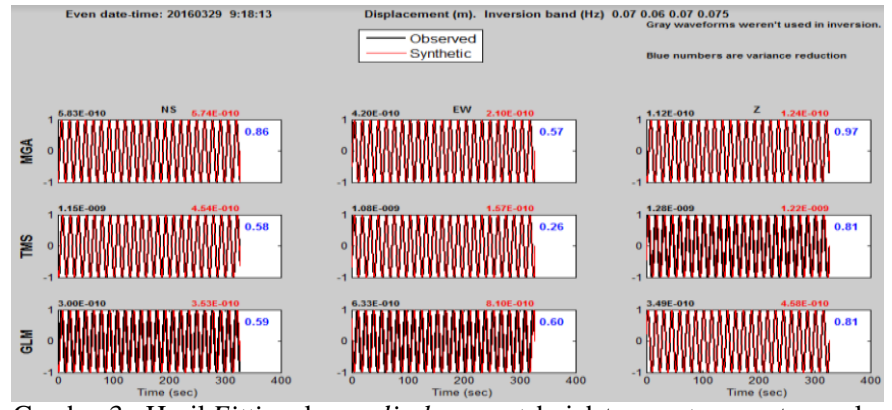

Gambar 3. Hasil Fittimg kurva displacement dari data event gempa tanggal 29/03/2016 pukul 9:18:13 WIB.

Tabel 3 .

Nilai Rentan Momen Tensor pada Setiap Event Gempa.

\begin{tabular}{ccccccc}
\hline \hline Event & $\mathrm{Mrr}$ & $\mathrm{M}_{\mathrm{tt}}$ & $\mathrm{M}_{\mathrm{pp}}$ & $\mathrm{M}_{\mathrm{rt}}$ & $\mathrm{M}_{\mathrm{rp}}$ & $\mathrm{M}_{\mathrm{tp}}$ \\
\hline $2016-10-27$ & 1.340 & -8.550 & 7.210 & 7.512 & 0.427 & 2.205 \\
$2016-10-09$ & -0.167 & -0.969 & 1.136 & 0.115 & 1.134 & -0.264 \\
$2016-06-19$ & -0.580 & -1.684 & 2.264 & 0.203 & -0.911 & -3.087 \\
$2016-06-07$ & 1.744 & -3.684 & 1.940 & 0.231 & -0.078 & -0.018 \\
$2016-06-04$ & -0.276 & -0.190 & 0.466 & 3.794 & 2.946 & 0.873 \\
$2016-03-29$ & 2.935 & -2.695 & -0.243 & -1.295 & 2.592 & -0.469 \\
\hline \hline
\end{tabular}

Tabel 4.

Nilai Rentan Momen Tensor pada Setiap Event Gempa.

\begin{tabular}{ccccccc}
\hline \hline \multirow{2}{*}{ Event } & \multicolumn{3}{c}{ Bidang 1 } & & \multicolumn{3}{c}{ Bidang 2 } \\
& Strike & Dip & Rake & Strike & Dip & Rake \\
\hline 20161027 & 236 & 86 & -36 & 328 & 54 & -175 \\
20161009 & 301 & 46 & 179 & 32 & 89 & 44 \\
20160619 & 106 & 78 & 176 & 197 & 86 & 12 \\
20160607 & 133 & 78 & 164 & 226 & 74 & 13 \\
20160604 & 351 & 7 & -152 & 233 & 87 & -83 \\
20160329 & 62 & 39 & 44 & 295 & 64 & 120 \\
\hline \hline
\end{tabular}

stasiun geophone pada Wilayah Maluku Utara, Indonesia dengan jangkauan awal hingga akhir tahun 2016. Gempa bumi berkisar pada magnitude lebih dari 4.9SR (Tabel 1).

\section{B. Pengolahan Data}

Setelah proses pengunduhan data selesai, dilanjutkan extracting data untuk mengkonversi data dalam bentuk SEED menjadi SAC supaya dapat diolah dalam program berikutnya. Extracting dilakukan dengan bantuan software JrdSeed dan CMD.Sebelum diolah pada program ISOLA-GUI yang dapat dijalankan oleh Matlab maka perludilakukan extracting data, supaya dapat diolah dalam program berikutnya yaitu dilakukan dengan bantuan software JrdSeed. Pengolahan data dengan menggunakan ISOLA bertujuan untuk mengetahui momen tensor dari data gempa, mennetukan jenis sesar serta parameter gempa yakni strike, dip dan rake [6]. (Tabel 2)

Krustal model untuk wilayah yang diteliti juga harus dimasukkan dalam ISOLA-GUI. Krustal model atau model bumi yang digunakan dalam penelitian ini ialah model bumi Has linger-Santosa. Modelbumi Has linger-Santosa adalah salah satu model kecepatan yang sesuai dengan kondisi bawah permukaan bumi di wilayah Indonesia. (Tabel 3) 
Tabel 5.

Nilai variance reduction Masing-masing Event.

\begin{tabular}{lc}
\hline \hline Event & $\begin{array}{c}\text { variance } \\
\text { reduction }\end{array}$ \\
\hline 20161027 & 0.87 \\
20161009 & 0.99 \\
20160619 & 0.53 \\
20160607 & 0.82 \\
20160604 & 0.92 \\
20160329 & 0.62 \\
\hline \hline
\end{tabular}

Nilai momen tensor (M) tersebut mempunyai satuan $\mathrm{Nm}$. Pada setiap event gempa yang terjadi, tercatat momen tensor bernilai berbeda-beda namun tidak sangat kontras. Besar nilai momen seis mik tersebut merupakan penggambaran model sesar penyebab gempa bumi tersebut. Dari inversi momen tensor dapatditentukan parameter jenis sesar (strike,dip dan rake). Dalam Tabel 4 disajikan besardari ketiga parameter jenis sesar.

Strike merupakan parameter sesar dengan sudut orientasi fault. Nilai pada kolom strike menunjukkan nilai sudut yang dibentuk oleh bidang patahan dengan permukaan horisontal. Strike dapat membuat sudut dari $0^{\circ}$ hingga $360^{\circ}$. Selanjutnya adalah kolom dip, dip adalah parameter sesar berupa sudut kemiringan fault. Nilai pada kolom dip dibentuk antara patahan dengan bidang horisontal. Dip dapat membuat sudut dari $0^{\circ}$ hingga $360^{\circ}$. Kemudian terdapat kolom rake yang menunjukkan nilai sudut pergerakan bidang terhadap kondisi strike.Pada setiap fenomena patahan, seolah-olah akan terdapat dinding atas dan dinding bawah. Rake inilah yang berperan untuk menunjukkan arah gerak dinding bagian atas akan bergerak naik atau turun secara diagonal. Ketika nilai rake $0^{\circ}$, ini berarti hanging wall atau sisi kanan dari patahan yang terlihat secara vertikal, seakan-akan menjauh dari ujung atas $0^{\circ}$ dan dapat dikatakan left lateral motion. Dan saat nilai rake $\pm 180^{\circ}$, hal ini dapat diartikan dinding atas seolah-olah mendekati ujung $0^{\circ}$ atau disebut right lateral motion [5].

\section{HASIL DAN DISKUSI}

Dari hasil solusi inversi akan memperoleh Momen tensor dan focal mechanism.Pada gempa yang terjadi tanggal 04/06/2016 dengan origin time 10:44:13 WIB menunjukan bahwa pola bidang yang terbentuk adalah normal fault dengan karakteristik untuk bidang pertama (hijau) besar strike $=351$, dip $=7$, dan rake $=-152$ dan bidang kedua (merah) besar strike $=233$, dip $=$ 87, dan rake $=-83$. Jarak antara hiposenter gempa dengan bidang pertama sebesar $11.74 \mathrm{~km}$ dan jarak dengan bidang kedua sebesar $17.40 \mathrm{~km}$, sehingga bidang patahannya adalah yang berwarna hijau dan auxiliary plane-nya berwarna merah. Untuk selisih kedalaman hiposenter dan centroidnya adalah 35 km (Gambar 2).

Momen tensor dan focal mechanism didapatkan dari hasil inversi momen tensor. Inversiditentukan oleh data seis mogram, fungsi green dan komponen momen tensor. Perhitungan fungsi green dan inversi menggunakan program ISOLA-GUI didapatkan hasil fitting kurva displacement dari data hasil observasi lapangan (seismogram) dengan data hasil estimasi menggunakan fungsi green (Gambar 3).
Tabel 6.

Komponen dari hasil studi

\begin{tabular}{cccccccc}
\hline \hline Event & $\mathrm{M}_{\mathrm{rr}}$ & $\mathrm{M}_{\mathrm{tt}}$ & $\mathrm{M}_{\mathrm{pp}}$ & $\mathrm{M}_{\mathrm{rt}}$ & $\mathrm{M}_{\mathrm{rp}}$ & $\mathrm{M}_{\mathrm{tp}}$ & $\mathrm{e}$ \\
\hline 20161027 & 1.340 & -8.550 & 7.210 & 7.512 & 0.427 & 2.205 & 17 \\
20161009 & -0.167 & -0.969 & 1.136 & 0.115 & 1.134 & -0.264 & 18 \\
20160619 & -0.580 & -1.684 & 2.264 & 0.203 & -0.911 & -3.087 & 16 \\
20160607 & 2.960 & -3.170 & 0.210 & 2.125 & -0.119 & 2.578 & 17 \\
20160604 & -3.924 & 5.393 & -1.469 & 1.609 & 1.353 & 2.486 & 16 \\
20160329 & 1.312 & 0.802 & -2.114 & -0.020 & -1.393 & -0.679 & 17 \\
\hline \hline
\end{tabular}

Kurva berwarna merah (Gambar 3) menunjukan estimasi dari fungsi green dan kurva berwarna hitam menunjukan data seismogram. Nilai kecocokan kurva ditentukan oleh variance reduction. Nilai variance reduction yang mendekati 1 menunjukkan bahwa fitting yang dilakukan mendekati presisi, dan ketika hasilnya mendekati 0 maka ketidak-presisiannya juga besar. Dalam Tabel 5 disajikan nilai variance reduction dari setiap event.

Hasil pola bidang patahan yang direpresentasikan dengan beachball didapatkan beberapa pola yang berbeda. Kebanyakan pusat gempa terdapat di Laut Maluku tepatnya di antara busur gunung aktif Halmahera dan busur gunung aktif Sangihe. Hal ini dikarenakan sangat tingginya tekanan yang bekerja pada lempeng tektonik Laut Maluku yang merupakan salah satu manifestasi aktivitas cincin api Pasific (Pasific Ring of Fire). Selaras dengan referensi yang mengatakan Kedua busur magmatik di daerah ini dipisahkan oleh jarak terdekat $250 \mathrm{~km}$, dimana masing-masing sisi busur terdapat palung dengan kedalaman hingga $3 \mathrm{~km}$. Diantara palung-palung tersebut dijumpai morfologi tinggi yaitu punggungan Mayu-Talaud yang pada beberapa tempat muncul kepermukaan sebagai pulau, yaitu Pulau Mayu, Pulau Talaud danPulauTifore. Gempa-gempa dangkal yang terkonsentrasikan di bawah puncak punggungan tersebut dan berdasarkanan analisis mekanisme fokal menunjukkan tipe sesar naik (reverse fault), selain itu juga terdapat normal fault dan strike slip fault mendominasi Laut Maluku yang terletak diantara kedua busur magmatik.

\section{KESIMPULAN}

Berdasarkan hasil data dan processing terhadap penelitian yang berjudul "Analisa Momen Tensor dan Mekanisme Pusat Gempa Bumi Wilayah Maluku Utara Sepanjang Tahun 2016 dengan Magnitude $\geq 5$ SR Memanfaatkan Program ISOLA GUI" dapat ditarik kesimpulan sebagai berikut:

1. Diperoleh masing-masing komponen sebesar (Tabel 6)

2. Pola focal mechanism bidang sesar wilayah Maluku Utara terdiri atas sesar naik (reverse fault) di dekat pulau Mayu dan Laut Maluku di dominasi oleh Pola bidang strike slip fault.

\section{DAFTAR PUSTAKA}

[1] D. Noor, Geologi Lingkungan, 1st ed. Yogyakarta: Graha Ilmu, 2006. [2] B. Hermanto, "Perkembangan Kerangka Tektonik Laut Maluku, Kepulauan Bangai-Sula dan Lajur Ofiolit Sulawesi Timur. Pusat Survei Geologi," J.G.S.M, vol.15, no.2, 2014.

[3] I. Ramadhani and B. Santosa, "Rwlokasi Hypocentre Gempa Bumi 
JURNAL SAINS DAN SENI ITS Vol. 7, No. 1 (2018) 2337-3520 (2301-928X Print)

Dengan Velest (JHD) dan Estimasi Sesar Daerah Sumatra Selatan," J. Fis. dan Apl., vol. 13, no. 2, 2017.

[4] T. K. Datta, "Seismic Analysis of Structures," New Delhi, 2010.
$[5]$

[6]

E. Sokos and J. Zahrandik, A Matlab GUIfor use with ISOLA Fontran codes. User's Guide, 2009.

C. V. . Murty, "IITK-BMPTC Earthquake Tips,” 2005. 